\title{
Insight into the Influence of Surface Roughness on the Wettability of Apatite and Dolomite
}

\author{
Xianchen Wang 1,2,3 and Qin Zhang 2,3,4,* \\ 1 College of Resources and Environmental Engineering, Guizhou University, Guiyang 550025, China; \\ xcwang1990@163.com \\ 2 College of Mining, Guizhou University, Guiyang 550025, China \\ 3 National \& Local Joint Laboratory of Engineering for Effective Utilization of Regional Mineral Resources \\ from Karst Areas, Guiyang 550025, China \\ 4 Guizhou Key Laboratory of Comprehensive Utilization of Non-metallic Mineral Resources, \\ Guiyang 550025, China \\ * Correspondence: qzhang@gzu.edu.cn; Tel.: +86-851-88292081
}

Received: 10 December 2019; Accepted: 27 January 2020; Published: 28 January 2020

\begin{abstract}
Surface roughness has an important influence on the wettability of particles. This paper is an innovative exploration to control the surface wettability of apatite and dolomite from the perspective of roughness in the background of phosphate flotation. Roughness characteristics of apatite and dolomite particles and its effects on wettability were investigated with surface roughness, contact angle measurements, and SEM analysis. The relationship between surface energy and wettability of different roughness surfaces was also discussed. The results indicated that the influence of roughness on apatite and dolomite particles showed the same regularity, and wettability increased with the increasing roughness for hydrophilic surfaces, while the wettability decreased for hydrophobic surfaces. The influence of roughness on wettability can be well explained by Wenzel and Cassie models, and the surface energy of different rough surfaces had a strong correlation with their wettability. When sodium oleate was added after acid treatment, the apatite was hydrophilic, while the dolomite was hydrophobic; the difference in wettability between them became greater as surface roughness increased. Thus, it can be predicted that the selective separation of dolomite and apatite under acid reverse flotation conditions can be strengthened by increasing the mineral surface roughness during comminution.
\end{abstract}

Keywords: apatite; dolomite; surface roughness; wettability; surface energy; flotation

\section{Introduction}

Phosphate ore is an important industry mineral resource in which apatite is the main valuable mineral. Over $90 \%$ of China's phosphate rock is high magnesium phosphate rock, and dolomite is the main carbonate gangue mineral of it. Flotation has been the most widely adopted technique for the separation of dolomite from apatite for this kind of magnesium (calcium) phosphate ore, and an anionic collector, such as sodium oleate, is usually used in the acidic pulp for reverse flotation [1-3]. Flotation is a separation method based on the difference of physical and chemical properties between valuable minerals and gangue minerals [4]. In the flotation process, in addition to particle size and shape [5-11], the wettability of mineral surface plays a decisive role in its floatability [12]. In previous studies, the contact angle between the mineral surface and the bubble is often used as an important indicator of the wettability of the mineral surface $[13,14]$.

As know from the literature, the surface chemical properties, such as element composition $[15,16]$, charge [17], and functional group [18], have an important influence on the wettability of minerals. 
However, the research about the influence of surface physical properties on mineral wettability is insufficient. The surface microstructure and roughness are important parts of mineral surface physical properties [9]. It has been shown that the surface roughness has an effect on the surface wettability or flotation performance of quartz [7,19,20], barite [21], malachite [22], glass beads [8], complex sulfide ores [23,24], coal [25] and so on. Calcite, barite, and quartz particles with different surface roughness were obtained by using a pulverizer, ball mill, and autogenous mill, and the contact angle measurements showed that the particles with the rougher surface had higher wettability [26]. Grinding with different mills also showed that the increase of roundness and roughness of particles due to grinding reduced the hydrophobicity or floatability of talc minerals [11]. In another study of grinding and flotation of barite using A-845 (Cytec) succinamate surfactant as a collector, the autogenous milling particles with lower acuteness and roughness had higher floatability than the corresponding products [27]. The flotation performances of the pyrite particles ground by different mills using a Hallimond tube suggested that the lower roughness and acuteness values caused higher flotation recoveries for the pyrite particles [28]. In turn, the flotation characteristics of glass beads with different roughness were studied using cetyltrimethylammonium bromide as a collector, and the results showed that the surface roughness improved the flotation recovery and bubble adhesion of glass beads [8]. Malachite ground with quartz of greater hardness had a rougher surface than that with montmorillonite, and therefore, showed a greater recovery after adsorption of the collector with a larger contact angle [22]. Ahmed [29] also found that the particles produced by dry milling had more rough surfaces and more microstructural defects compared with wet milling, the mineralized foam of them was more stable, and the flotation speed was faster during the flotation process. In addition to these minerals, it was also found in the literature [30] that a higher/lower roughness did not directly lead to a higher/lower natural wettability of the coal surface. The wettability of natural/gold-coated coal surface increased with the increase of surface roughness first, decreased second, and then had a little increase. At the same time, the influence of roughness on mineral wettability was also reflected by the studies of bubble-particle attachment time measurements. The results showed that the attachment time for sulfur particles with a relatively smooth surface was longer than that of particles with a rough surface [31,32]. While another research reported that the attachment time increased with the increase of roughness of coal surfaces, which is considered to be caused by the reduction of the contact area between the rougher surface and the bubble [10]. Chen et al. suggested the same conclusion that both the attachment time and contact angle decreased with the increase of roughness, and they pointed out that the reason may be that the contact of the bubbles with the coal surface was hindered by the retention of water in the cracks and pores of the rough coal surface [33].

Although these studies tried to reveal the effect of roughness on the wettability of mineral surface, the true relationship between roughness and mineral wettability was still insufficient. In some cases, the results were even inconsistent. However, the influence of roughness on the wettability of mineral surfaces certainly existed $[6,8,9,22,23,26,29,33]$. In the flotation process, due to the same metal cation calcium in the lattice, apatite and dolomite showed similar crystal properties and surface physical and chemical properties, so it is difficult to achieve effective separation. Therefore, the control of surface wettability is of great significance. Although there have been many studies on the flotation separation technology and development of flotation reagents of apatite and dolomite [2,34-37], few studies on the influence of roughness on the wettability of mineral surface have been carried out. For the flotation system of apatite and dolomite, it could be a new insight to enhance the surface wettability from the perspective of roughness.

This study aimed to investigate the influence of roughness on the wettability of apatite and dolomite surfaces before and after the modification of a flotation reagent (collector and $\mathrm{pH}$ regulator). Apatite and dolomite samples with different surface roughness were prepared by polishing with different mesh numbers of sandpapers. A MarsurfM400 surface roughness device and scanning electron microscopy (SEM) were carried out to describe the surface roughness and morphology characteristics of samples. Contact angle measurement was used to study the wettability of minerals. 
The Wenzel and Cassie wetting models were further used to explain the results of roughness and wettability, and the relationship between surface energy and wettability of different roughness surfaces was discussed. The results may provide some new insights to enhance the wettability difference of apatite and dolomite, and take into consideration the flotation separation of them.

\section{Materials and Methods}

\subsection{Materials}

Natural apatite and dolomite samples were obtained from Wengfu Plant in Guizhou Province, China. The single minerals were selected by hand first, and the X-ray diffraction (XRD) (X'Pert PRO, PANalytical Company, Almelo, the Netherlands) test was used to identify the mineral composition and purity of the polished samples (Figure 1). The XRD results showed that the peak of the apatite sample was the same as that of the fluorapatite, which indicated that the main component of the apatite sample was fluorapatite. The XRD of the dolomite sample was consistent with the standard dolomite peak. The apatite and dolomite samples were of high purity and could be used as a single mineral for experimental research. These mineral lumps were cut into small pieces of about $10 \mathrm{~mm} \times 10 \mathrm{~mm} \times 5 \mathrm{~mm}$ for contact angle and roughness measurements.

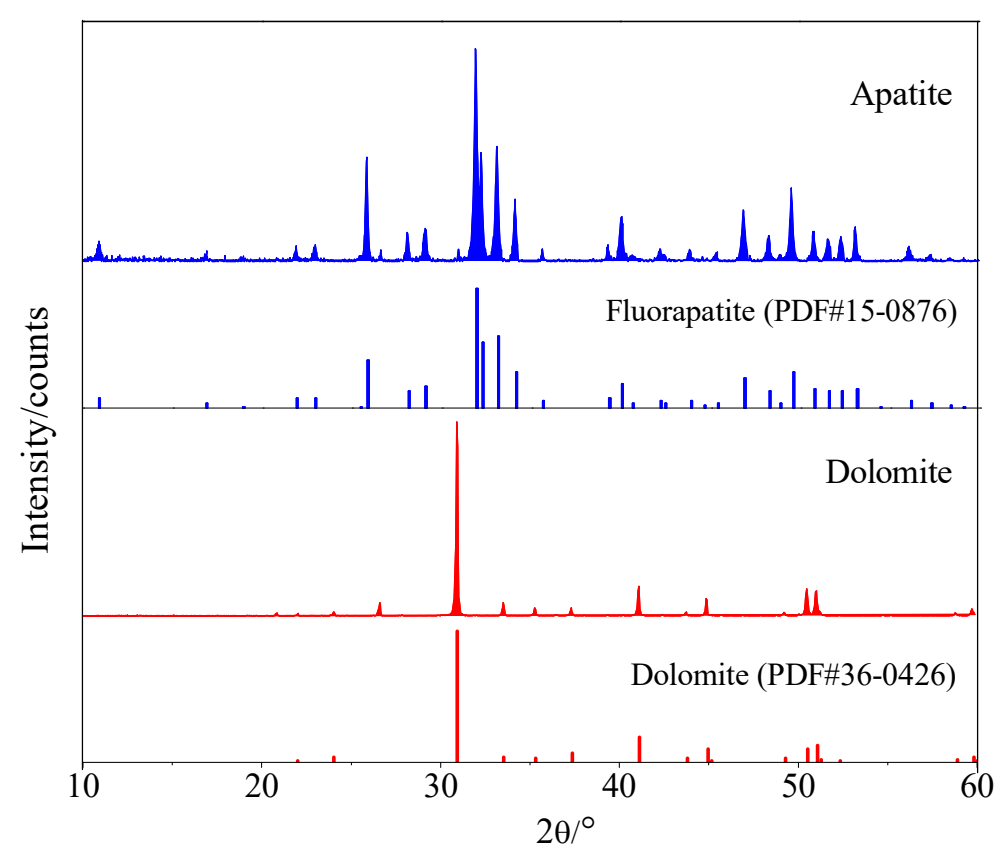

Figure 1. X-ray diffraction results of apatite and dolomite samples.

The analytical collectors of sodium oleate (NaOL) and phosphoric acid obtained from Sinopharm Chemical Reagent Co.,Ltd were used for contact angle studies, and the Formamide and Diiodomethane analytical reagents obtained from Aladdin were used for the surface energy calculations. All the water used in the research was deionized (DI) (Milli-Q, $18.25 \mathrm{M} \Omega \cdot \mathrm{cm})$.

\subsection{Polishing Treatment}

To gain flat surfaces of mineral particles with various surface roughness, the mineral lumps were polished using 2000 mesh, 1000 mesh, 240 mesh, and 80 mesh silicon carbide sandpaper, respectively, and recorded as surface A, B, C, and D, in which surface A was further polished with alumina polishing powder of $1.0 \mu \mathrm{m}, 0.3 \mu \mathrm{m}$ and $0.05 \mu \mathrm{m}$, and a silk polishing cloth. The surfaces of all samples were thoroughly cleaned by ethanol and deionized water under ultrasonic waves, and then dried at low 
temperature. These flat mineral surfaces with various surface roughness values were used for the surface roughness and contact angle measurements and scanning electron microscope (SEM) analysis.

\subsection{Surface Roughness Measurements}

Quantitative characterization of surface roughness of mineral surfaces was investigated using the MarSurf M400 surface measurement instrument (Mahr, Göttingen, Germany) as shown in Figure 2. Parameters that characterize surface roughness are marked with the letter $R a$ (dimensionless), which is the arithmetic mean deviation of the contour, that is, the arithmetic means of the absolute value of the ordinate value within a certain traversing length. This has been widely used in characterizing the roughness of material surfaces $[9,25,30]$. The traversing length for all the samples was set at $5.60 \mathrm{~mm}$. The roughness value of each mineral particle was measured three times, and the final value was obtained using the arithmetic mean.

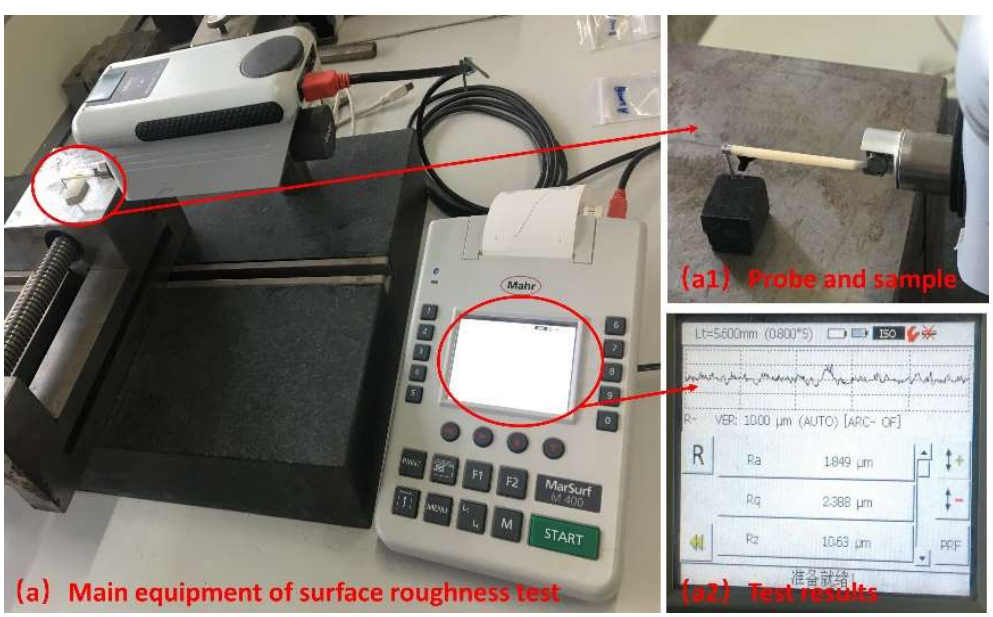

Figure 2. Surface roughness measuring instrument (MarSurf M400) ((a) Main eauipment of surface roughness measurement; (a1) Probe and sample; (a2) Test results).

The surface morphology of each polished mineral surface was analyzed using the SEM ( $I$ IGMA+X-Max20, ZEISS, Oberkochen, Germany). The test voltage was set to 5000 volts. The magnification times were fixed at 50 and 500. Before the SEM testing, each mineral surface was sputter-coated with a layer of gold. It should be noted that the wettability of the mineral surface was studied before the pretreatment of SEM gold plating.

\subsection{Surface Tension Measurements}

The surface tension of the NaOL solutions was measured using the Wilhelmy plate method (JK99B, Powereach, Shanghai, China) [38]. Before the preparation of the NaOL solution, the glassware was cleaned with ethanol and then washed with DI water. Before each measurement, the platinum plate was burned on the alcohol flame to remove any organic contamination. About $20 \mathrm{~mL} \mathrm{NaOL} \mathrm{solution}$ was used for each test.

\subsection{Contact Angle Measurements}

The contact angle measurements were carried out to characterize the wettability of mineral surfaces. The droplet method was used to measure the contact angle of the mineral surface (HARKE-SPCAX3, Beijing Hake Test Instrument Factory, Beijing, China) as seen in Figure 3. The specific steps were as follows [37]: The mineral was immersed in a certain concentration of the collector solution for $12 \mathrm{~h}$ and then naturally dried and placed on the test platform. A water droplet with a volume of about $2 \mu \mathrm{L}$ was squeezed out by a syringe and then dropped on to the mineral surface slowly and automatically. After the droplet spread stably on the mineral surface (about $5 \mathrm{~s}$ ), the "baseline circle" in the instrument's 
software was used. Each contact angle was measured three times at different surface areas, and the final value was determined using the arithmetic mean value.

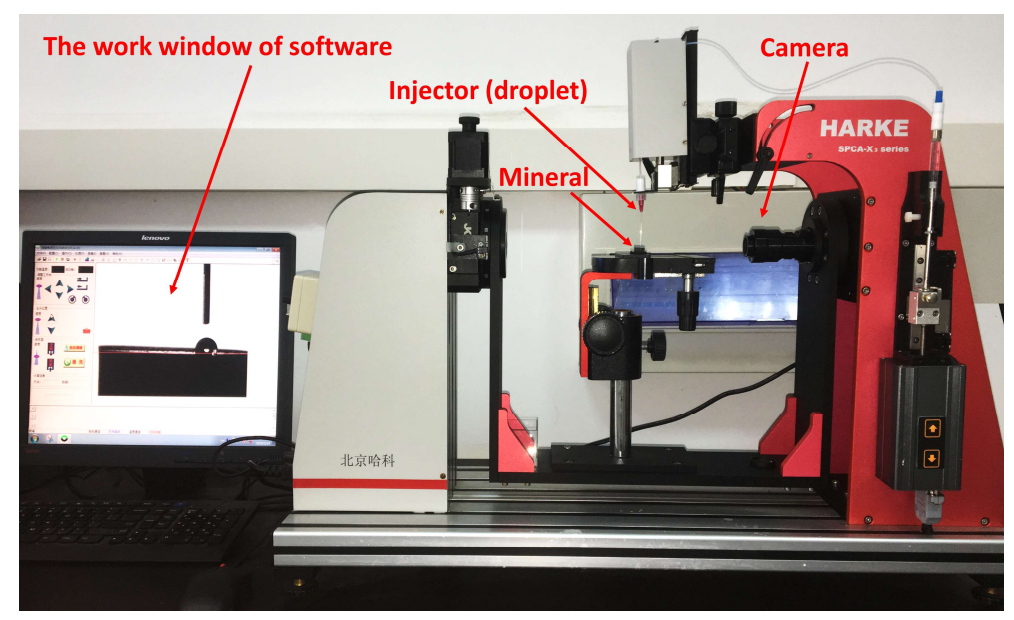

Figure 3. Contact angle measurement instrument (HARKE-SPCAX3).

\subsection{Surface Energy Measurements}

Up to now, there has not been an effective method to measure the surface energy of solid materials directly. In this study, the surface energy of minerals was measured by Owens's three liquid method, which has been introduced in detail in the literature [39] and is based on the Young's Equation.

Young's Equation describes the relationship among the solid surface energy $\gamma_{S}$, liquid surface energy (surface tension) $\gamma_{L}$, solid/liquid interfacial interaction free energy $\gamma_{S L}$, solid surface pressure $\pi_{0}$, and balance contact angle $\theta$ in the solid/liquid/gas triple-phase system as follows.

$$
\gamma_{S}-\pi_{0}-\gamma_{S L}=\gamma_{L} \cos \theta
$$

For the low energy surface, surface pressure $\pi_{0}$ can be negligible; Young's Equation is turned into Equation (2):

$$
\gamma_{S}-\gamma_{S L}=\gamma_{L} \cos \theta
$$

Van Oss argued that solid/liquid surface energy $\gamma$ is composed of Lifshitz-van der Waals(LW) component $\gamma^{L W}$ and Lewis acid-base(AB) component $\gamma^{A B}$, and $\gamma^{A B}$ is composed of Lewis acid component $\gamma^{+}$and Lewis base component $\gamma^{-}$. Consequently, with regards to solid/liquid, surface energy can be denoted by:

$$
\begin{aligned}
& \gamma_{S}=\gamma_{S}^{L W}+\gamma_{S}^{A B}=\gamma_{S}^{L W}+2 \sqrt{\gamma_{S}^{+} \gamma_{S}^{-}} \\
& \gamma_{L}=\gamma_{L}^{L W}+\gamma_{L}^{A B}=\gamma_{L}^{L W}+2 \sqrt{\gamma_{L}^{+} \gamma_{L}^{-}}
\end{aligned}
$$

The connection between solid/liquid interfacial free energy and solid/liquid respective surface energy can be denoted by:

$$
\gamma_{S L}=\left(\sqrt{\gamma_{S}^{L W}}-\sqrt{\gamma_{L}^{L W}}\right)^{2}+2\left(\sqrt{\gamma_{S}^{+} \gamma_{S}^{-}}+\sqrt{\gamma_{L}^{+} \gamma_{L}^{-}}-\sqrt{\gamma_{S}^{+} \gamma_{L}^{-}}-\sqrt{\gamma_{S}^{-} \gamma_{L}^{+}}\right)
$$

Substituting Equations (3)-(5) into Equation (2), we can get the connection among solid surface energy, liquid surface energy and the balance contact angle between them.

$$
\left(\gamma_{L}^{L W}+2 \sqrt{\gamma_{L}^{+} \gamma_{L}^{-}}\right)(1+\cos \theta)=2\left(\sqrt{\gamma_{S}^{L W} \gamma_{S}^{L W}}+\sqrt{\gamma_{S}^{+} \gamma_{L}^{-}}+\sqrt{\gamma_{S}^{-} \gamma_{L}^{+}}\right)
$$


Therefore, the solid surface energy parameters $\gamma_{S}^{L W}, \gamma_{S}^{+}, \gamma_{S}^{-}$can be obtained by mensurating the contact angle between the solid surface and the three kinds of liquid with the given the values of $\gamma_{L}^{L W}$, $\gamma_{L}^{+}, \gamma_{L}^{-}$(two of the three must be polar liquid).

It was found that the combination schemes of water-glycerin-diiomethane, water-formamidediiomethane and water-glycol-diiomethane can reflect the surface characteristics of polymer well [40]. Thus, the group of water-formamide-diiodomethane was selected as the standard liquid in this study. The surface tension components of the liquid (polar liquids of water, formamide and diiodomethane) are listed in Table 1.

Table 1. The surface tension components of the three liquids.

\begin{tabular}{ccccc}
\hline Examined Liquid & $\gamma_{L}^{\text {total }}$ & $\gamma_{L}^{L W}$ & $\gamma_{L}^{+}$ & $\gamma_{L}^{-}$ \\
\hline Second Purified & 72.8 & 21.8 & 25.5 & 25.5 \\
Water & 50.8 & 50.8 & 0 & 0 \\
Diiodomethane & 58.0 & 39.0 & 2.3 & 39.6 \\
Formamide & &
\end{tabular}

\subsection{Micro-Flotation of Single Mineral}

Micro-flotation tests on a single mineral $(45-75 \mu \mathrm{m})$ were carried out as a function of the collector concentration in a $40 \mathrm{~mL}$ XFGCII flotation machine (mechanical agitation). Firstly, $2.0 \mathrm{~g}$ of mineral samples were placed in a plexiglass cell in which $40 \mathrm{~mL}$ DI water were filled. After 2 min agitation at $1992 \mathrm{rpm}$, the collector was added into the cell with 2 min conditioning time (when adjusting the pulp $\mathrm{pH}$, phosphoric acid was added before the collector and stirred for only $30 \mathrm{~s}$ ), and then flotation was conducted for another $3 \mathrm{~min}$. The froth and sink products were separately filtered, dried, weighed, and assayed. Data from assay was used to calculate the flotation recovery. Each group of single mineral flotation was repeated three times and the average flotation recovery was calculated.

\section{Results}

\subsection{Surface Roughness and Morphology Characteristics}

The results of roughness measurements at different surfaces of apatite and dolomite are shown in Figure 4.

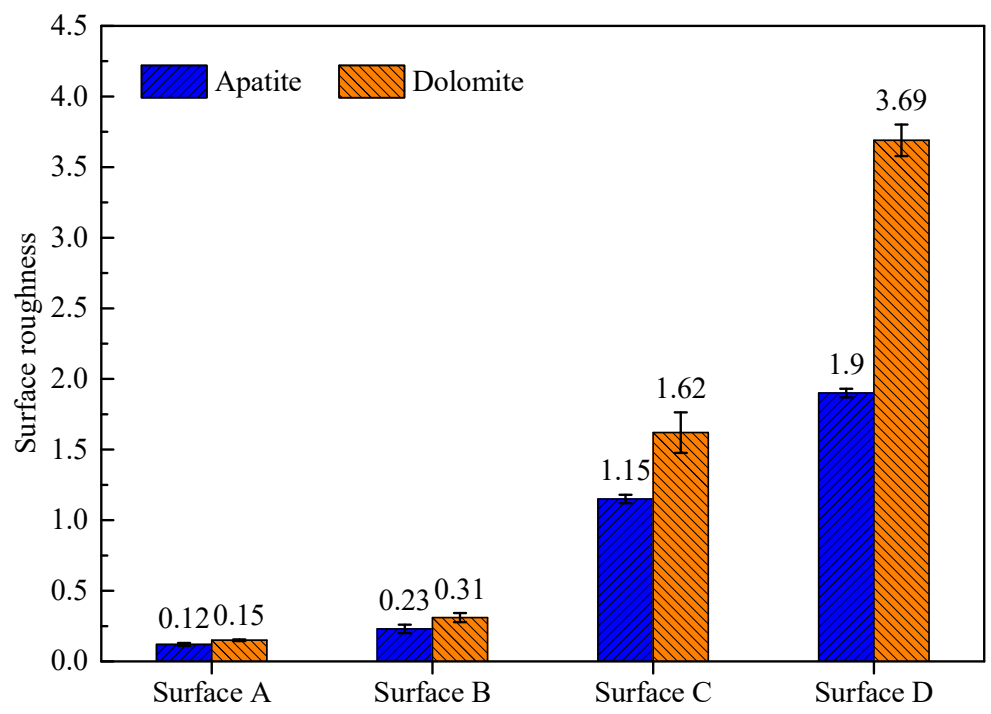

Figure 4. Surface roughness of apatite and dolomite sanded with different sandpapers. 
As shown in Figure 4, four groups of apatite and dolomite with different roughnesses were obtained by different sandpaper treatments. The $R a$ values of the samples decreased with the increase of meshes of sandpapers. $R a$ value varied from $0.12 \mu \mathrm{m}$ to $1.90 \mu \mathrm{m}$ for apatite from surface A to surface $\mathrm{D}$, and from 0.15 and 3.69 for dolomite, respectively. The change of $R a$ indicated that the roughness of the four surfaces was quite different, which was expected to have a significant impact on the wetting behavior of the mineral surfaces.

At the same time, comparing the surface roughness of apatite and dolomite treated with the same mesh of sandpaper, the surface roughness of dolomite was larger than that of apatite. This may be due to the difference in Mohs hardness of apatite and dolomite. The Mohs hardness of apatite is about 5 , while that of dolomite is about 3.5-4. This also showed that in the actual process of ore crushing and grinding, the properties of apatite and dolomite will show differences; because of this, the dolomite is softer and easier to be crushed and ground.

The difference of surface roughness morphology between apatite and dolomite is also shown by SEM in Figures 5 and 6.

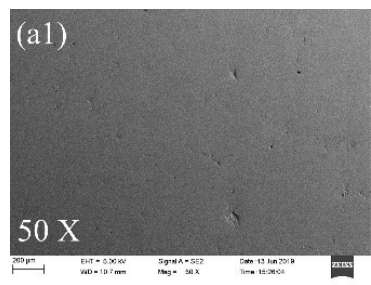

$R a=0.12$

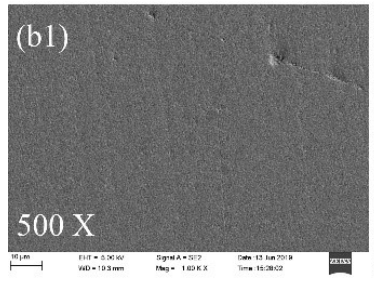

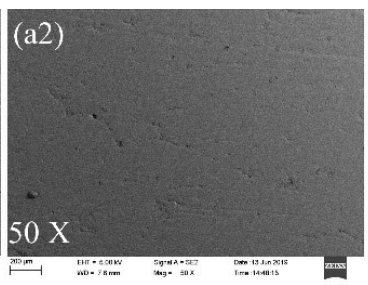

$R a=0.23$

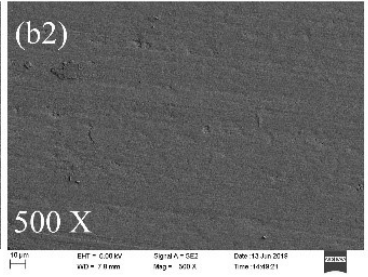

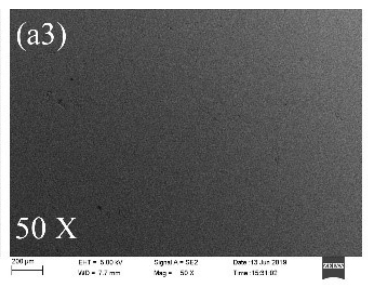

$R a=1.15$

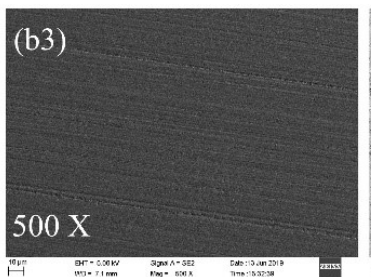

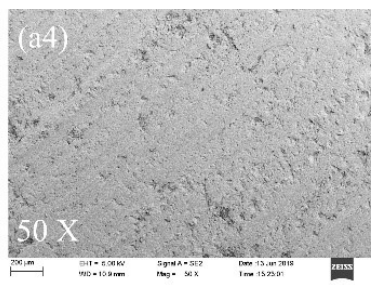

$R a=1.90$

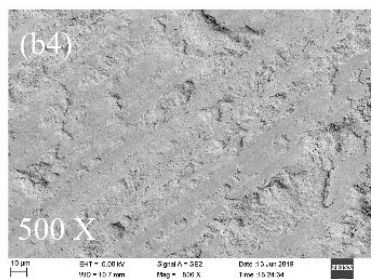

Figure 5. Surface morphology of apatite with different roughness by SEM. (a1) and (b1) are 50 and 500 times enlarged views of surface A, respectively; (a2) and (b2) are 50 and 500 times enlarged views of surface B, respectively; (a3) and (b3) are 50 and 500 times enlarged views of surface $C$, respectively; (a4) and (b4) are 50 and 500 times enlarged views of surface D, respectively.

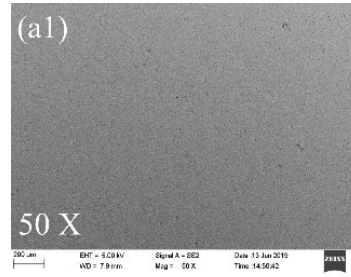

$R a=0.15$

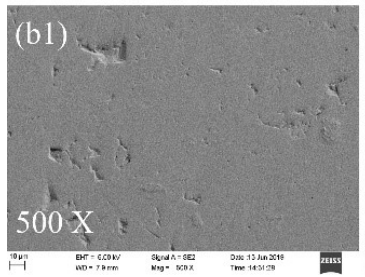

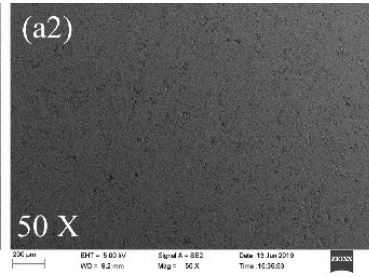

$R a=0.31$

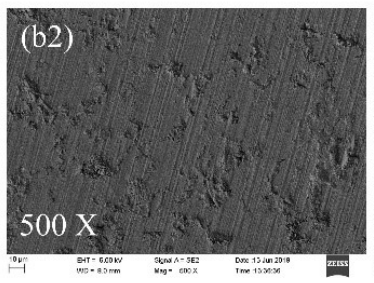

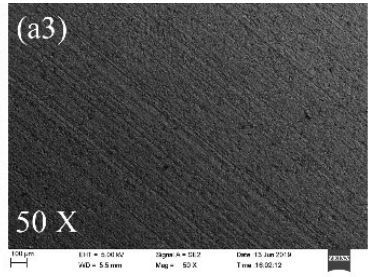

$R a=1.62$

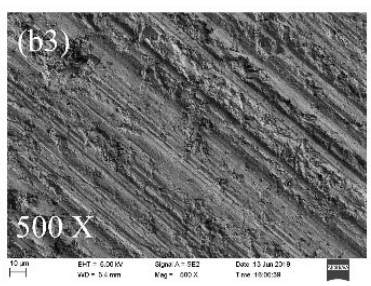

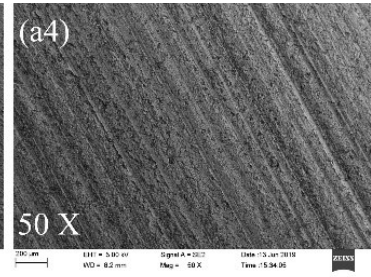

$R a=3.69$

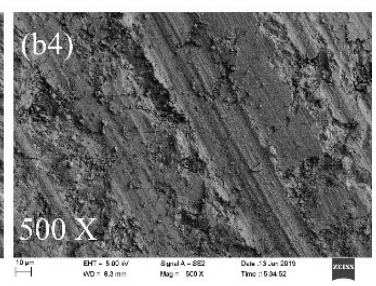

Figure 6. Surface morphology of dolomite with different roughness by SEM. (a1) and (b1) are 50 and 500 times enlarged views of surface A, respectively; (a2) and (b2) are 50 and 500 times enlarged views of surface B, respectively; (a3) and (b3) are 50 and 500 times enlarged views of surface $C$, respectively; (a4) and (b4) are 50 and 500 times enlarged views of surface D, respectively. 
Through the SEM analysis results seen in Figures 5 and 6, it is clear that the surface morphology and structure of different roughness showed significant differences. It indicated that the mineral surface became smoother by using higher meshes of sandpaper. The rough mineral surface had many grooves and tiny holes, and the width and depth of the surface grooves with different surface roughness were different. The higher the surface roughness, the greater the width and depth of the grooves. Under the same mesh of sandpaper treatment, the surface of dolomite had larger groove width and depth than that of apatite, and the surface was shown to be rougher, which was also consistent with the test results of roughness value. The width and depth of the grooves suggested having a significant effect on the wetting process of water on the mineral surface. In some cases, the groove can promote the wetting process of water droplets on the mineral surface, but it can also hinder the wetting process by entraining air.

\subsection{Effect of Surface Roughness on Contact Angle of Apatite and Dolomite Surfaces}

To reveal the effect of surface roughness on the wettability of apatite and dolomite surfaces in the background of the flotation process, the different wetting characteristics of apatite and dolomite surface were obtained with different treatments including various concentrations of collector. It has been well established that $\mathrm{NaOL}$ is a powerful collector for oxidized ore, such as apatite [37], dolomite [41], fluorite [42], pyrochlore [43], malachite [22], and so on. When it adsorbed on apatite and dolomite surfaces, it changed the hydrophilic mineral surface to hydrophobic [2,44]. However, when the concentration of $\mathrm{NaOL}$ exceeded the critical micelle concentration (CMC), the mineral surface became hydrophilic again due to the double-layer adsorption of NaOL molecules on mineral surfaces [37,45].

To determine the appropriate concentration of $\mathrm{NaOL}$, the surface tension of different concentrations of NaOL solution was measured in advance to determine its semi micelle concentration (Figure 7).

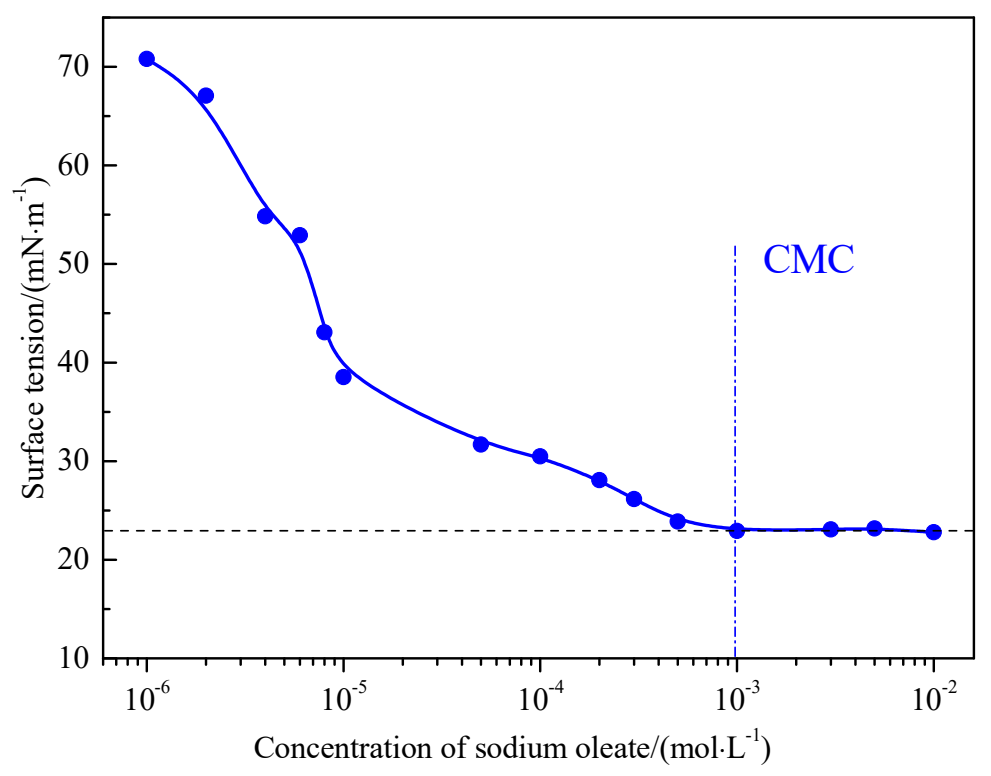

Figure 7. Surface tension of NaOL solution as a function of concentration.

The results indicated that the CMC of $\mathrm{NaOL}$ was approximately $1 \times 10^{-3} \mathrm{~mol} / \mathrm{L}$, which is consistent with the results in the literature [37]. On the other hand, for the beneficiation of calcium magnesium phosphate ore, the reverse flotation was a widely used high-efficiency separation process using the sulfuric acid, phosphoric acid, etc. as the adjusting agent to remove dolomite. The typical apatite and dolomite single minerals flotation recovery are displayed in Figure 8. The natural floatability of apatite and dolomite particles was quite poor. When a certain concentration of NaOL was added, the floatation recoveries of them were both over $80 \%$, but there was a lack of separation selectivity. When the phosphoric acid was used to adjust the $\mathrm{pH}$ before the collector, the recovery of dolomite 
particles decreased slightly, but it still had good floatability, while apatite particles were strongly inhibited, and the floatability decreased to about $20 \%$, indicating that they had a good separation selectivity under acidic conditions [1,2].

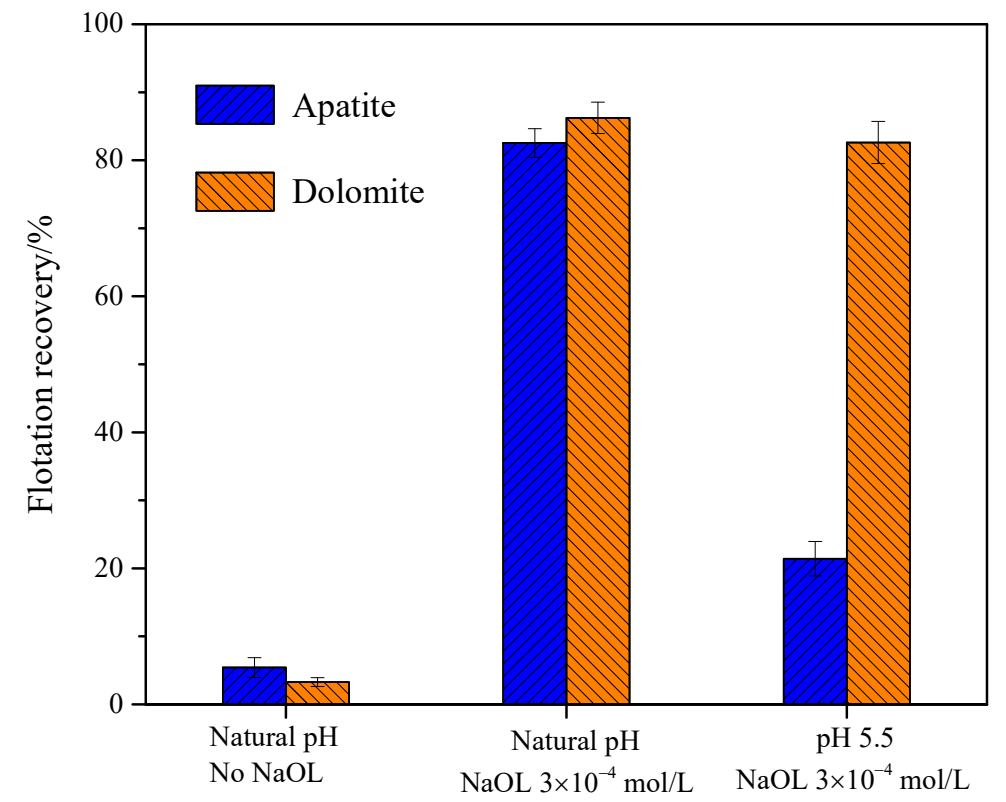

Flotation condition

Figure 8. Recovery of apatite and dolomite in the presence of different concentrations of NaOL at natural $\mathrm{pH}$ and $\mathrm{pH}$ of about 5.5 .

Based on this, four groups of different conditions were chosen to treat apatite and dolomite to obtain different wettability of mineral blocks. The first group was treated without $\mathrm{NaOL}$ at natural $\mathrm{pH}$, the second was treated with different concentrations of NaOL $\left(3 \times 10^{-5} \mathrm{~mol} / \mathrm{L}, 3 \times 10^{-4} \mathrm{~mol} / \mathrm{L}\right.$, and $3 \times 10^{-3} \mathrm{~mol} / \mathrm{L}$ ) under natural $\mathrm{pH}$ condition, and the third was treated by adding a concentration of $3 \times 10^{-4} \mathrm{~mol} / \mathrm{L} \mathrm{NaOL}$ after adjusting $\mathrm{pH}$ at about 5.5 with phosphoric acid.

(1) Natural wettability in the absence of $\mathrm{NaOL}$

The contact angles of apatite and dolomite surfaces with different surface roughness without NaOL treatment are shown in Figure 9.
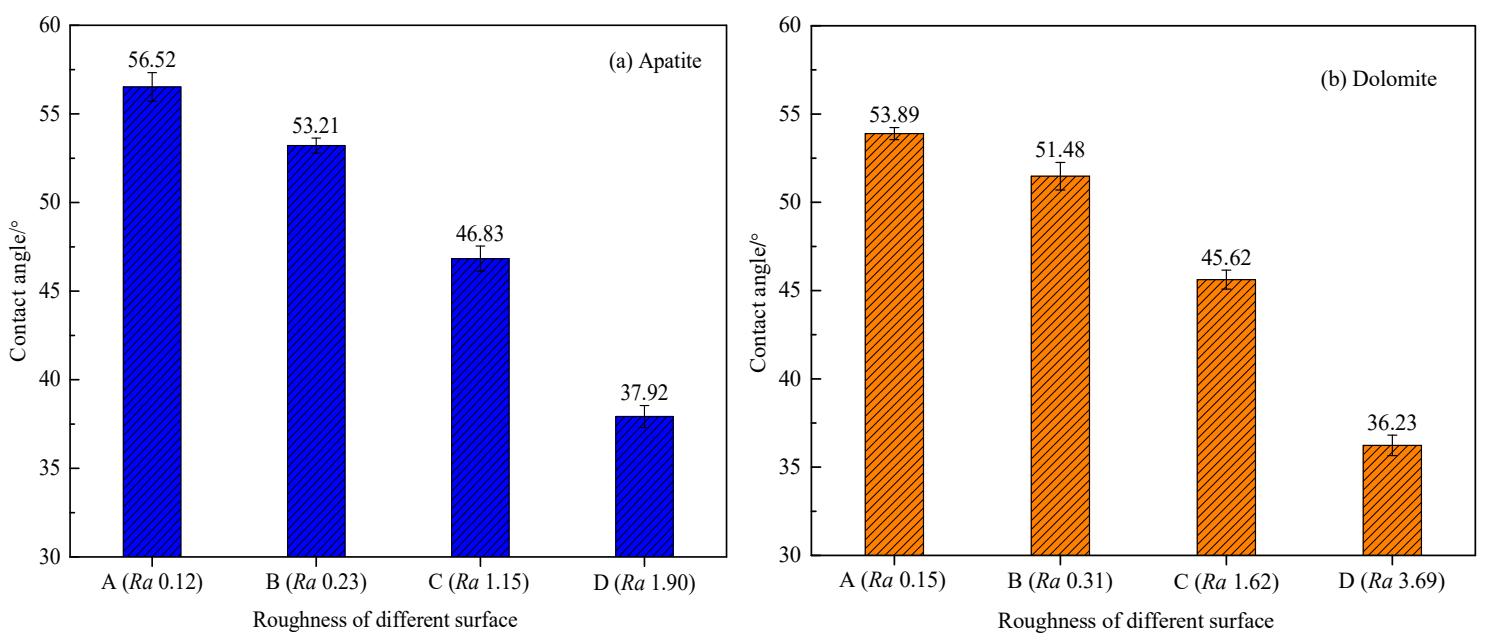

Figure 9. Effect of surface roughness on contact angle of (a) apatite and (b) dolomite surfaces at natural $\mathrm{pH}$ in the absence of $\mathrm{NaOL}$. 
Contact angles of the surfaces of natural apatite and dolomite were around $36^{\circ}$ to $56^{\circ}$, and the difference between them was small (Figure 9). Previous studies have reported that the surface of apatite was hydrophilic with a contact angle of about $10^{\circ}$ [13]. However, these angles in Figure 9 were larger than the theoretical values of a hydrophilic apatite or dolomite surface. This finding may be related to the organic matter of black collophane that originates from black shales in sedimentary rocks [37] as the apatite and dolomite single mineral were selected from the sedimentary phosphorite. It was consistent with the result reported in the literature that the contact angle of a natural smooth polished apatite block was about $58^{\circ}$ by the captive bubble method [37]. Thus, they were still considered as relatively hydrophilic surfaces. The contact angle of apatite decreased from $56.5^{\circ}$ to $37.9^{\circ}$ from surface A to surface $\mathrm{D}$, and that of dolomite decreased from $53.89^{\circ}$ to $36.23^{\circ}$. Both hydrophilic apatite and dolomite showed the rule that the rougher the surface, the stronger the natural hydrophilicity.

(2) natural $\mathrm{pH}$ in the presence of $\mathrm{NaOL}$

The effect of surface roughness on the contact angle of apatite and dolomite surfaces at natural $\mathrm{pH}$ in the presence of $\mathrm{NaOL}$ addition is shown in Figures 10 and 11.
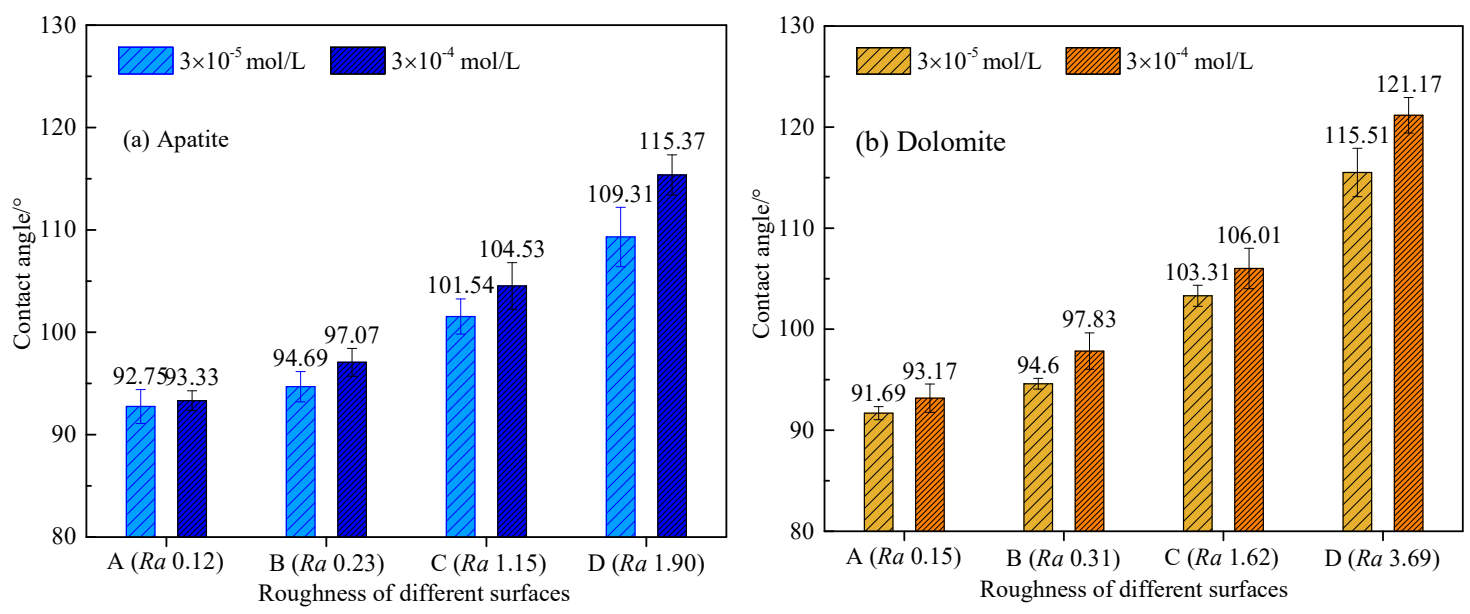

Figure 10. Effect of surface roughness on contact angle of (a) apatite and (b) dolomite surfaces at natural $\mathrm{pH}$ in the presence of $\mathrm{NaOL}\left(3 \times 10^{-5} \mathrm{~mol} / \mathrm{L}\right.$ and $\left.3 \times 10^{-4} \mathrm{~mol} / \mathrm{L}\right)$.

As shown in Figure 10, the surfaces of apatite and dolomite both showed to be hydrophobic after $\mathrm{NaOL}$ concentrations of $3 \times 10^{-5} \mathrm{~mol} / \mathrm{L}$ and $3 \times 10^{-4} \mathrm{~mol} / \mathrm{L}$ treatment, and the effect of roughness on the two hydrophobic surfaces at these two concentrations was consistent. The contact angle of apatite surface A, B, C, and D changed to $93.33^{\circ}, 97.07^{\circ}, 104.53^{\circ}$, and $115.37^{\circ}$, respectively, at the NaOL concentration of $3 \times 10^{-4} \mathrm{~mol} / \mathrm{L}$, and that of dolomite also changed to $93.17^{\circ}, 97.83^{\circ}, 106.01^{\circ}$, and $121.17^{\circ}$, respectively. These indicated that, whether for hydrophobic apatite or dolomite particles, the contact angle values increased with the increase of surface roughness, that is, the wettability decreased as the surface roughness increased. On the other hand, the increase of adsorption of $\mathrm{NaOL}$ on roughness may contribute to the change of wettability. The rough surface increased the adsorption site of $\mathrm{NaOL}$ on its surface, so under the same projection area, the amount of $\mathrm{NaOL}$ adsorbed on the rough surface increased, resulting in the increase of contact angle on the mineral surface. In the research of surface roughness with collector treatment, the increase of contact angle may be caused by the above two reasons. This viewpoint was also supported by the study of wettability of sodium oleate on the rough malachite surface [22].

When the concentration of $\mathrm{NaOL}$ increased to $3 \times 10^{-3} \mathrm{~mol} / \mathrm{L}$, which exceeded the critical CMC, the surfaces of apatite and dolomite both changed to be hydrophilic again (Figure 11). These abrupt changes in the surface wettability considered that the NaOL had double-layer adsorption on the mineral surface [37]. At this condition, the hydrophilic group and hydrophobic group of the NaOL was suggested to cross-form double-layer adsorption on the mineral surface, leading to a two-headed 
hydrophilic structure. One end of the hydrophilic group was adsorbed on the surface of the mineral, and the other end of the hydrophilic group was exposed in the water, resulting in the final hydrophilicity of the mineral surface. The contact angle of apatite surface was further reduced from $48.52^{\circ}$ to $28.91^{\circ}$ with the increase of roughness, and that of dolomite was correspondingly reduced from $56.5^{\circ}$ to $33.82^{\circ}$. This indicated that the contact angles decreased with the increase of roughness, that was to say, the wettability of the surface became greater. It was consistent with the effect of roughness on the natural hydrophilic surface of apatite and dolomite. These results showed that the rougher the hydrophilic surface was, the more hydrophilic it was, whether it was natural hydrophilic or adjusted by flotation agent.
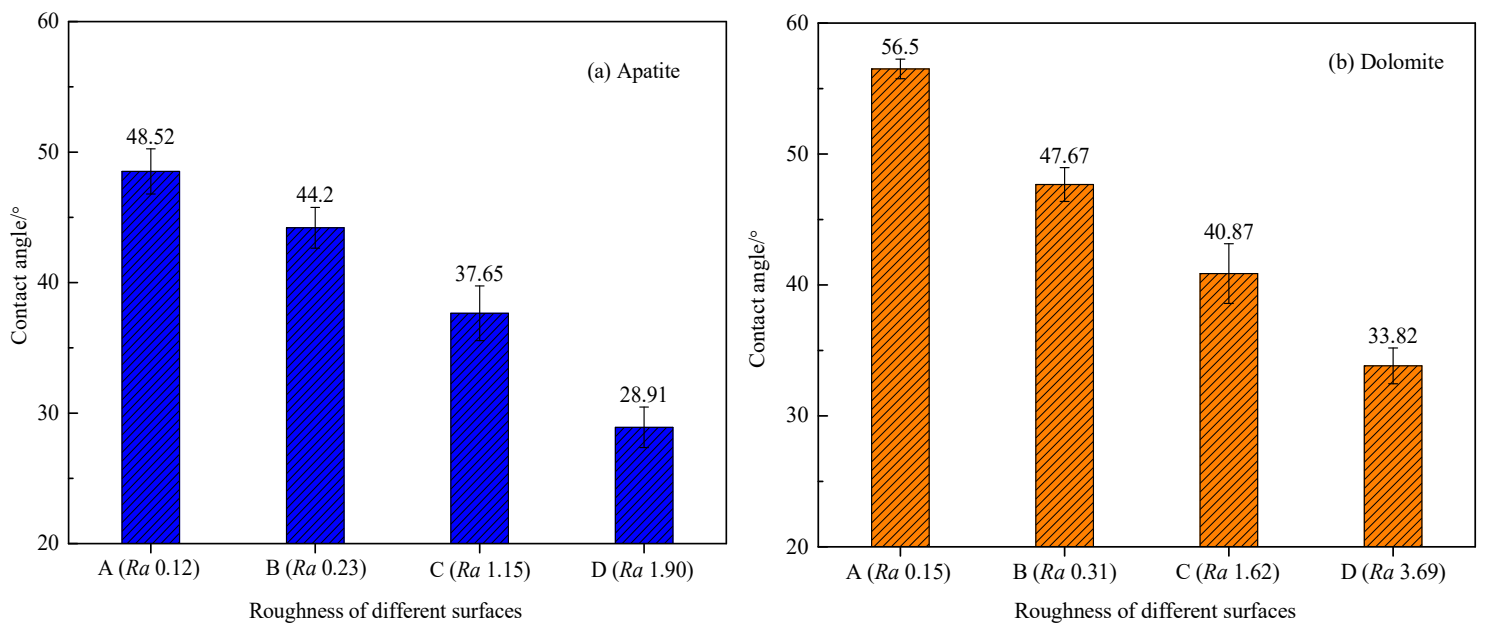

Figure 11. Effect of surface roughness on contact angle of (a) apatite and (b) dolomite surfaces at natural $\mathrm{pH}$ in the presence of $\mathrm{NaOL}\left(3 \times 10^{-3} \mathrm{~mol} / \mathrm{L}\right)$.

(3) In the presence of $\mathrm{NaOL}$ after phosphoric acid treatment.

The contact angle of different apatite and dolomite surfaces with different roughness with NaOL addition $\left(3 \times 10^{-4} \mathrm{~mol} / \mathrm{L}\right)$ after phosphoric acid treatment at $\mathrm{pH}$ of about 5.5 can be seen in Figure 12 .

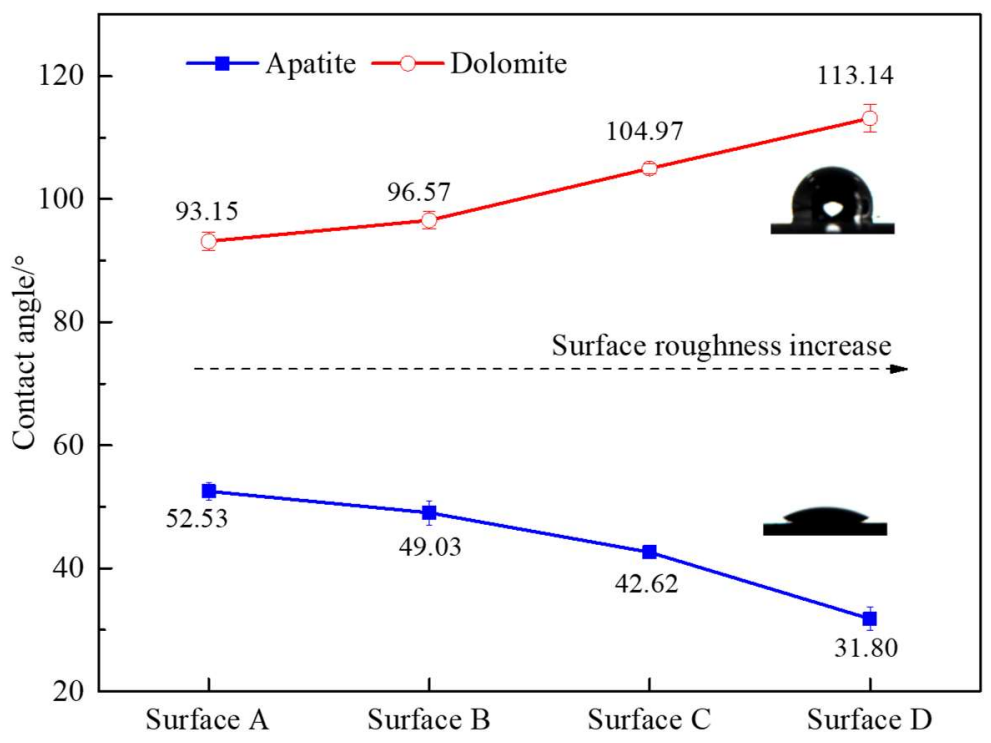

Figure 12. Effect of surface roughness on contact angle of apatite and dolomite surfaces in the presence of $\mathrm{NaOL}\left(3 \times 10^{-4} \mathrm{~mol} / \mathrm{L}\right)$ after phosphoric acid treatment at $\mathrm{pH}$ about 5.5. 
It can be seen in Figure 12 that when NaOL was added after the acid treatment, the surface of apatite was hydrophilic, while that of dolomite was hydrophobic. As the surface roughness increased, the contact angle of apatite surface decreased from $52.53^{\circ}$ to $31.80^{\circ}$, i.e., the hydrophilicity of the surface increased; the contact angle of dolomite surface increased from $93.15^{\circ}$ to $113.14^{\circ}$, i.e., the hydrophobicity of the surface increased. By comparing the two, it was found that the wettability difference of apatite and dolomite became greater as surface roughness increased, which was beneficial to the flotation separation of them. This suggested that the difference of wettability between apatite and dolomite could be enlarged by adjusting the surface roughness of them, and then the difference of floatability between them was expected to enlarge to strengthen the flotation separation. Previous studies [7,9-11,26,46,47] had also proven that this insight was feasible, in which the size and shape of mineral particles could be changed by controlling grinding, thus affecting their surface roughness. Grinding the malachite with quartz can improve the surface roughness of malachite particles, and then improve its floatability [22]. Based on the literature [29], particles produced by dry milling have more rough surfaces and more microstructural defects compared with wet milling, the mineralized foam of them is more stable, and the flotation speed is faster during the flotation process. It has been suggested that in the flotation of calcareous phosphate ore, a relatively coarse grinding size will result in rougher particles, which is more conducive to the flotation between mineral particles under the condition that the dissociation of the mineral is guaranteed. While for the fine-grained minerals, a one-stage milling stage flotation process may be more suitable to obtain rougher particles.

\subsection{Surface Wetting Model}

The contact angle test results of the influence of surface roughness on the surface of apatite and dolomite can be well described by the Wenzel model [48]. It is a classical model to explain the influence of surface roughness on contact angle, especially for materials. According to the Wenzel model, the real contact area of the solid-liquid interface on the rough surface is larger than the apparent contact area (Figure 13), and the tiny gap and groove on the rough surface can be filled completely by the liquid (as shown in the Figures $13 \mathrm{~b}$ and 14b); therefore, the apparent contact angle of the rough surface $\theta_{m}$ is related to the intrinsic contact angle (Young's contact angle) $\theta_{r}$ of the flat surface as follows:

$$
\cos \theta_{m}=\frac{r\left(\gamma_{S G}-\gamma_{S L}\right)}{\gamma_{L G}}=r \cdot \cos \theta_{r}
$$

In Equation (7), $r$ is the roughness factor (equal to the ratio of the actual contact area of the solid-liquid interface to its projected area, $r \geq 1$ ). From Equation (7), it can be seen that for the original hydrophilic surface, the larger the $r$ value is, the smaller the $\theta_{m}$ is; for the original hydrophobic surface, the larger the $r$ value is, the larger the $\theta_{m}$ is. When the roughness increases, the wettability of the hydrophilic surface becomes better, while the wettability of the hydrophobic surface further decreases.

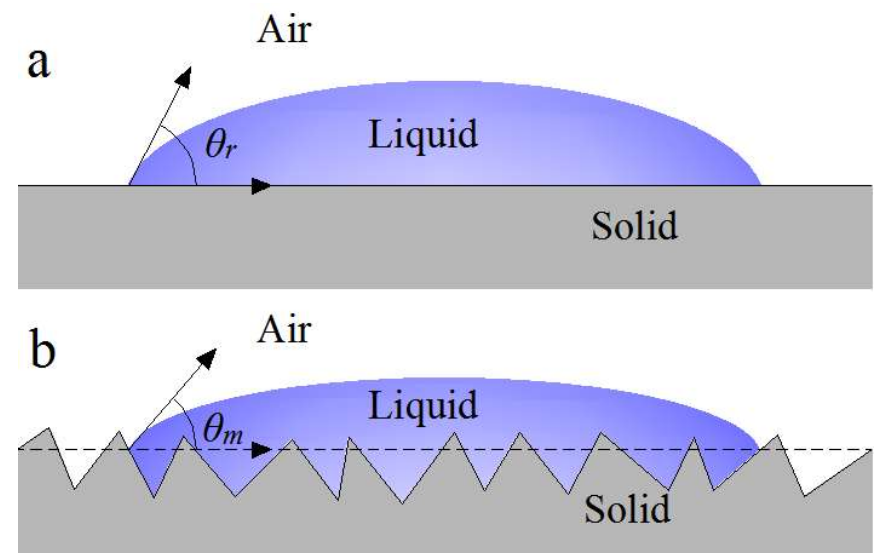

Figure 13. Wet state model of a hydrophilic surfaces: (a) Young model; (b) Wenzel model. 
For apatite and dolomite, the surface roughness increased from surface A to D. According to the Wenzel equation, the contact angle of the hydrophilic apatite and dolomite samples on surface A should be the smallest, that is, the wettability is the best; for the hydrophobic surface, the contact angle on surface D should be the largest, that is, the hydrophobicity is the strongest. The predicted results were in good agreement with those of the contact angle test.

For a hydrophobic surface, Cassie and Baxter [49] extended the rough surface to heterogeneous surfaces and put forward the Cassie model (Figure 14c). It considers that the droplet on the hydrophobic surface cannot fully fill the groove on the rough surface, and there is a bubble between the liquid and the solid contact surface groove, which is also called an air pocket [25]. It is believed that the air filled between the droplets and the solid surface is an extreme superhydrophobic medium. Water droplets can be considered to be ideally spherical in air, so the intrinsic contact angle can be assumed to be $180^{\circ}$. Therefore, when the solid-liquid-gas composite contact surface reaches thermodynamic equilibrium, the apparent contact angle $\theta_{m}$ of the rough surface is the average value of the intrinsic contact angle (Young's contact angle) $\theta_{r}$ of the flat surface and $180^{\circ}$, that is, the following relationship:

$$
\cos \theta_{m}=f_{s} \cdot\left(1+\cos \theta_{r}\right)-1
$$

where $f_{s}$ is the ratio of the area of the protruding solid in the composite contact surface to the total contact area, from which it can be seen that for the originally hydrophobic surface, the smaller the $f_{\mathcal{S}}$ is, the larger the $\theta_{m}$ is. That is, increasing the proportion of the air pocket portion will enhance the superhydrophobic property of the solid surface.
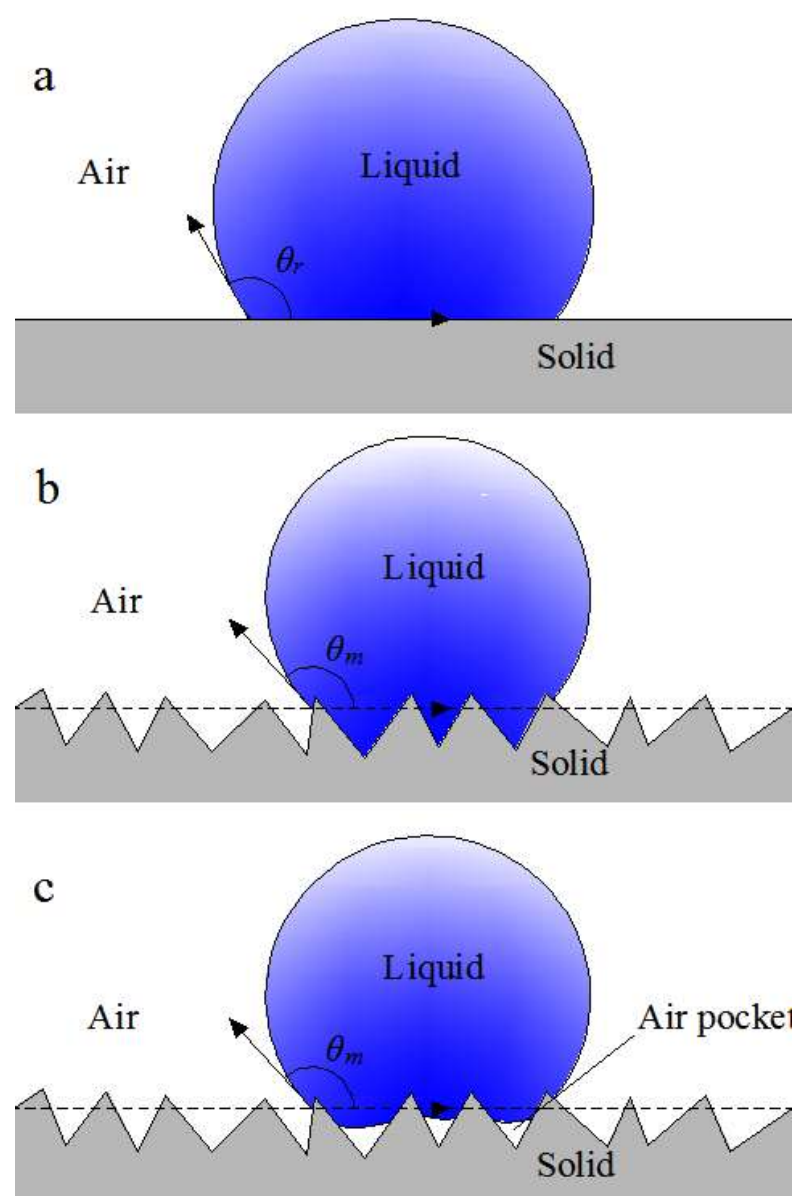

Figure 14. Wet state model of a hydrophobic surface: (a) Young model; (b) Wenzel model; (c) Cassie. 
Based on this theory, the roughness of surface A was the smallest, and the surface was the smoothest, so the proportion of the air pocket portion accounted for the least area, and the wetting state is like the Young model shown in Figure 14a. When the roughness of surfaces increases, the proportion of air pocket increases correspondingly, and the contact angle should increase in the order of surface roughness from small to large. This is also consistent with the contact angle test results. The Cassie model was considered to be more accurate than the Wenzel model in reflecting the effect of a real rough surface [50].

\subsection{The Relationship between Surface Roughness, Surface Energy, and Wettability}

Surface energy is the main driving force for the formation of solid surface characteristics and surface phenomena and is an important physical quantity to describe and determine the wettability of the solid surface [39]. In general, the higher the surface free energy of the solid, the better the wettability of water droplets on the solid surface and the smaller the contact angle. The lower the surface free energy is, the more the contact angle will be. The relationship between surface roughness, surface energy and wettability for the natural hydrophilic mineral surface and the hydrophobic mineral surface due to NaOL addition is displayed in Figures 15 and 16, respectively.

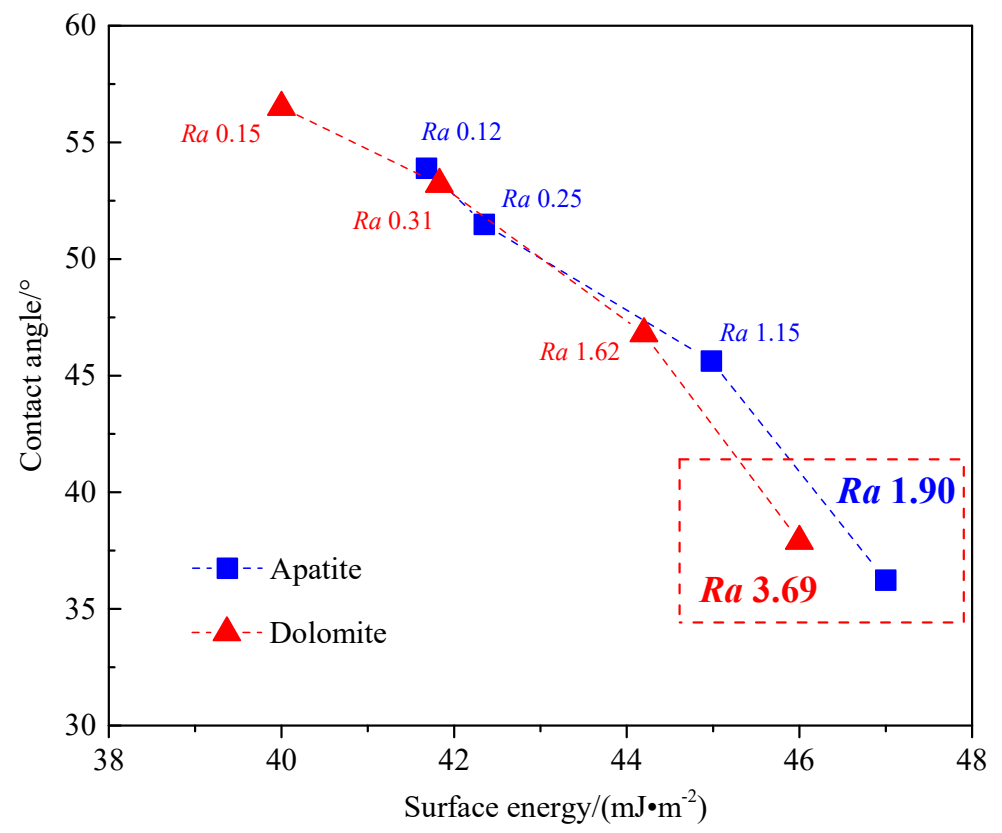

Figure 15. The relationship between surface roughness, surface energy and wettability for the natural hydrophilic mineral surface.

It can be seen from Figure 15 that for the natural hydrophilic apatite and dolomite surfaces, with the increase of surface roughness, the surface energy of apatite and dolomite increased gradually, and the contact angle decreased gradually, that is, the wettability increased gradually. This could be interpreted as, for the mineral surface with a larger surface energy, water tended to spread on the surface to reduce the surface energy, and the surface was wetting. For the natural mineral surface, the larger the surface roughness was, the larger the surface energy was, i.e., the stronger the surface hydrophilicity was.

It can be seen from Figure 16 that the adsorption of $\mathrm{NaOL}$ on the apatite and dolomite surface made the surface energy of them decrease rapidly, and water tended to contract on the solid surface. The mineral surface was hydrophobic. However, different from the natural surface, with the increase of surface roughness, the solid surface energy decreased, and the surface hydrophobicity became stronger. The surface energy of the solid was determined by the interaction of surface roughness and 
the adsorption of NaOL [22]. The collector and water formed competitive adsorption on the mineral surface. The NaOL tended to adsorb on the mineral surface preferentially so that the surface energy of the mineral surface could be reduced and the surface appears hydrophobic. The rougher the surface, the larger the adsorption capacity adsorption density of the surface collector, and then the smaller the surface energy. This was consistent with the results of the above contact angle results. Overall, roughness has a certain effect on mineral surface energy, and the surface energy of different rough surfaces has a strong correlation with their wettability.

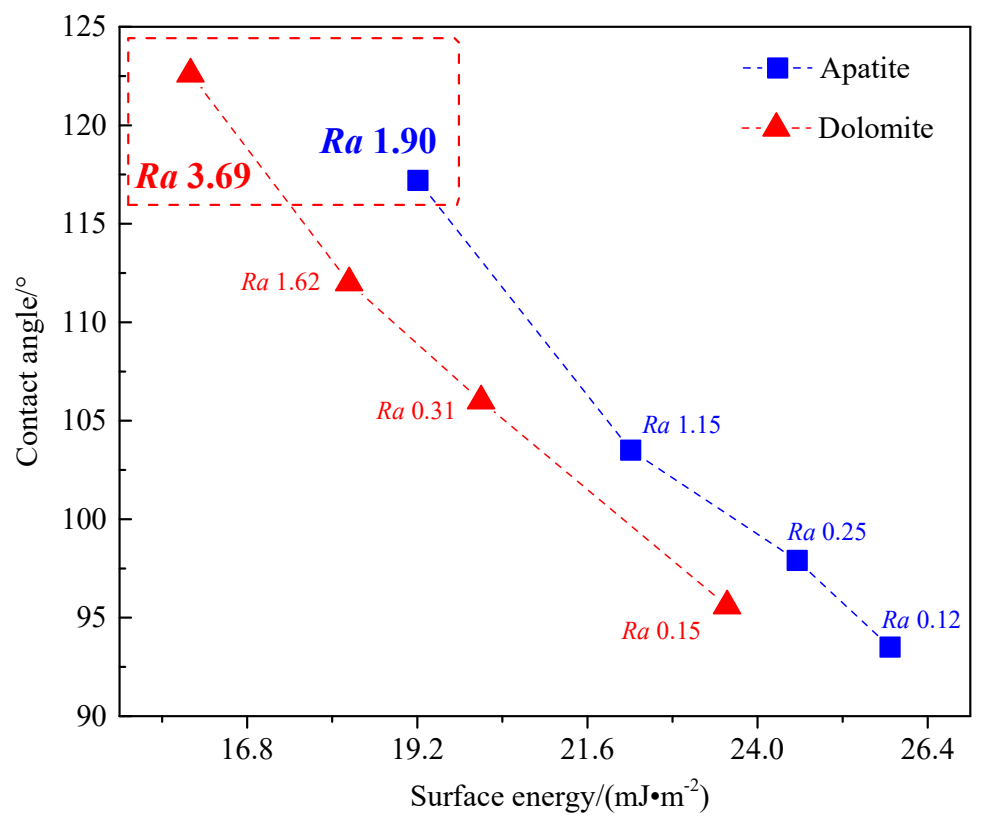

Figure 16. The relationship between surface roughness, surface energy and wettability for the hydrophobic mineral surface due to $\mathrm{NaOL}$ addition $\left(3 \times 10^{-4} \mathrm{~mol} / \mathrm{L}\right)$.

\section{Conclusions}

The influence of roughness on the wettability of apatite and dolomite surfaces before and after the modification of flotation reagent (collector and $\mathrm{pH}$ regulator) were investigated; this provided new insights to enhance the wettability difference for apatite and dolomite. The surface roughness of dolomite (Mohs hardness 3.5-4) under the same mesh sandpaper treatment was larger than that of apatite (Mohs hardness 5). The effect of surface roughness on the wettability of apatite and dolomite was consistent with Wenzel's and Cassie's surface wettability theory, meaning, for the hydrophilic surface, the higher the roughness was, the stronger the hydrophilicity; and for the hydrophobic surface, the rougher the surface, the more hydrophobic the surface. This rule applied to surfaces of both natural wettability and those adjusted by a flotation agent. Roughness had a certain effect on mineral surface energy, and the surface energy of different rough surfaces showed a strong correlation with their wettability. The difference in wettability became greater between apatite and dolomite when the surface roughness increased through the addition of NaOL after acid treatment. Thus, this suggested that the selective separation of dolomite from apatite under acidic conditions using a reverse flotation can be strengthened by increasing the mineral surface roughness during comminution.

Author Contributions: X.W. and Q.Z. conceived and designed the experiments; X.W. performed all the experiments, data analysis and wrote the original manuscript; Q.Z. contributed the experiment resources, helped to analysis the test results and participated in the manuscript modification. All authors have read and agreed to the published version of the manuscript.

Funding: This research was funded by the National Nature Science Foundation of China (U1812402). 
Acknowledgments: Thanks to Yong Liu from the College of Mechanical Engineering of Guizhou University for helping to complete the surface roughness test of the sample.

Conflicts of Interest: The authors declare no conflict of interest.

\section{References}

1. Yu, J.; Ge, Y.Y.; Guo, X.; Guo, W. The depression effect and mechanism of NSFC on dolomite in the flotation of phosphate ore. Sep. Purif. Technol. 2016, 161, 88-95. [CrossRef]

2. Sis, H.; Chander, S. Reagents used in the flotation of phosphate ores: A critical review. Miner. Eng. 2003, 16, 577-585. [CrossRef]

3. Liu, X.; Li, C.; Luo, H.; Cheng, R.; Liu, F. Selective reverse flotation of apatite from dolomite in collophanite ore using saponified gutter oil fatty acid as a collector. Int. J. Miner. Process. 2017, 165, 20-27. [CrossRef]

4. Rao, S.R. Surface Chemistry of Froth Flotation, 2nd ed.; Springer Science and Business Media: New York, NY, USA, 2004.

5. Ulusoy, U.; Hiçyılmaz, C.; Yekeler, M. Role of shape properties of calcite and barite particles on apparent hydrophobicity. Chem. Eng. Process. 2004, 43, 1047-1053. [CrossRef]

6. Ulusoy, U.; Yekeler, M. Floatability of barite particles with different shape and roughness. Indian J. Chem. Techn. 2007, 14, 616-625.

7. Ulusoy, U.; Yekeler, M.; Hiçyılmaz, C. Determination of the shape, morphological and wettability properties of quartz and their correlations. Miner. Eng. 2003, 16, 951-964. [CrossRef]

8. Vaziri Hassas, B.; Caliskan, H.; Guven, O.; Karakas, F.; Cinar, M.; Celik, M.S. Effect of roughness and shape factor on flotation characteristics of glass beads. Colloids Surf. A Physicochem. Eng. Asp. 2016, 492, 88-99. [CrossRef]

9. Xia, W.C. Role of particle shape in the floatability of mineral particle: An overview of recent advances. Powder Technol. 2017, 317, 104-116. [CrossRef]

10. Xia, W.C.; Ma, G.X.; Bu, X.N.; Peng, Y.L. Effect of particle shape on bubble-particle attachment angle and flotation behavior of glass beads and fragments. Powder Technol. 2018, 338, 168-172. [CrossRef]

11. Yekeler, M.; Ulusoy, U.; Hiçyılmaz, C. Effect of particle shape and roughness of talc mineral ground by different mills on the wettability and floatability. Powder Technol. 2004, 140, 68-78. [CrossRef]

12. Wonyen, D.; Kromah, V.; Gibson, B.; Nah, S.; Chelgani, S. A review of flotation feparation of Mg carbonates (dolomite and magnesite). Minerals 2018, 8, 354. [CrossRef]

13. Sis, H.; Chander, S. Adsorption and contact angle of single and binary mixtures of surfactants on apatite. Miner. Eng. 2003, 16, 839-848. [CrossRef]

14. Santos, E.P.; Dutra, A.J.B.; Oliveira, J.F. The effect of jojoba oil on the surface properties of calcite and apatite aiming at their selective flotation. Int. J. Miner. Process. 2015, 143, 34-38. [CrossRef]

15. Xia, W.C.; Yang, J.G. Changes in surface properties of anthracite coal before and after inside/outside weathering processes. Appl. Surf. Sci. 2014, 313, 320-324. [CrossRef]

16. Xia, W.C.; Yang, J.G.; Liang, C. Investigation of changes in surface properties of bituminous coal during natural weathering processes by XPS and SEM. Appl. Surf. Sci. 2014, 293, 293-298. [CrossRef]

17. Quast, K. Literature review on the interaction of oleate with non-sulphide minerals using zeta potential. Miner. Eng. 2016, 94, 10-20. [CrossRef]

18. Chang, Z.Y.; Chen, X.M.; Peng, Y.J. Understanding and improving the flotation of coals with different degrees of surface oxidation. Powder Technol. 2017, 321, 190-196. [CrossRef]

19. Rahimi, M.; Aslani, M.R.; Rezai, B. Influence of surface roughness on flotation kinetics of quartz. J. Cent South Univ 2012, 19, 1206-1211. [CrossRef]

20. Guven, O.; Ozdemir, O.; Karaagaclioglu, I.E.; Çelik, M.S. Surface morphologies and floatability of sand-blasted quartz particles. Miner. Eng. 2015, 70, 1-7. [CrossRef]

21. Yekeler, M.; Ulusoy, U. Characterisation of surface roughness and wettability of salt-type minerals: Calcite and barite. Miner. Process. Extr. Metall. 2004, 113, 145-152. [CrossRef]

22. Li, Z.L.; Rao, F.; Corona-Arroyo, M.A.; Bedolla-Jacuinde, A.; Song, S.X. Comminution effect on surface roughness and flotation behavior of malachite particles. Miner. Eng. 2019, 132, 1-7. [CrossRef]

23. Karakas, F.; Hassas, B.V. Effect of surface roughness on interaction of particles in flotation. Physicochem. Probl. Miner. Process. 2016, 52, 18-34. 
24. Krasowska, M.; Malysa, K. Kinetics of bubble collision and attachment to hydrophobic solids: I. Effect of surface roughness. Int. J. Miner. Process. 2007, 81, 205-216. [CrossRef]

25. Xing, Y.W.; Zhang, Y.F.; Liu, M.; Xu, M.D.; Guo, F.Y.; Han, H.S.; Gao, Z.Y.; Cao, Y.J.; Gui, X.H. Improving the floatability of coal with varying surface roughness through hypobaric treatment. Powder Technol. 2019, 345, 643-648. [CrossRef]

26. Ulusoy, U.; Yekeler, M. Correlation of the surface roughness of some industrial minerals with their wettability parameters. Chem. Eng. Process. 2005, 44, 555-563. [CrossRef]

27. Hicyilmaz, C.; Ulusoy, U.; Bilgen, S.; Yekeler, M. Flotation responses to the morphological properties of particles measured with three-dimensional approach. Int. J. Miner. Process. 2005, 75, 229-236. [CrossRef]

28. Akdogan, G.; Hicyilmaz, C.; Ulusoy, U.; Bilgen, M.S. Response of rough and acute surfaces of pyrite with 3-D approach to the flotation. J. Min. Sci. 2006, 42, 393-402.

29. Ahmed, M.M. Effect of comminution on particle shape and surface roughness and their relation to flotation process. Int. J. Miner. Process. 2010, 94, 180-191. [CrossRef]

30. Xia, W.C.; Ni, C.; Xie, G.Y. The influence of surface roughness on wettability of natural/gold-coated ultra-low ash coal particles. Powder Technol. 2016, 288, 286-290. [CrossRef]

31. Dippenaar, A. The destabilization of froth by solids. I. The mechanism of film rupture. Int. J. Miner. Process. 1982, 9, 1-14. [CrossRef]

32. Dippenaar, A. The destabilization of froth by solids. II. The rate-determining step. Int. J. Miner. Process. 1982, 9, 15-22. [CrossRef]

33. Chen, Y.R.; Xia, W.C.; Xie, G.Y. Contact angle and induction time of air bubble on flat coal surface of different roughness. Fuel 2018, 222, 35-41. [CrossRef]

34. Hoang, D.H.; Hassanzadeh, A.; Peuker, U.A.; Rudolph, M. Impact of flotation hydrodynamics on the optimization of fine-grained carbonaceous sedimentary apatite ore beneficiation. Powder Technol. 2019, 345, 223-233. [CrossRef]

35. Ruan, Y.Y.; He, D.S.; Chi, R.A. Review on beneficiation techniques and reagents used for phosphate ores. Minerals 2019, 9, 253. [CrossRef]

36. Xie, J.; Li, X.H.; Mao, S.; Li, L.J.; Ke, B.L.; Zhang, Q. Effects of structure of fatty acid collectors on the adsorption of fluorapatite (001) surface: A first-principles calculations. Appl. Surf. Sci. 2018, 444, 699-709. [CrossRef]

37. Ye, J.J.; Zhang, Q.; Li, X.B.; Wang, X.C.; Ke, B.L.; Li, X.H.; Shen, Z.H. Effect of the morphology of adsorbed oleate on the wettability of a collophane surface. Appl. Surf. Sci. 2018, 444, 87-96. [CrossRef]

38. Li, X.B.; Zhang, Q.; Hou, B.; Ye, J.J.; Mao, S.; Li, X.H. Flotation separation of quartz from collophane using an amine collector and its adsorption mechanisms. Powder Technol. 2017, 318, 224-229. [CrossRef]

39. Gu, G.H.; Wang, H.; Suo, J.; Qiu, G.Z.; Hao, Y. Interfacial interaction of bio-leaching of pyrite mineral. J. Cent. South Univ. Technol. 2008, 15, 49-53. [CrossRef]

40. Wang, H.; Gu, G.H.; Qiu, G.Z. Evaluation of surface free energy of polymers by contact angle goniometry. J. Cent. South Univ. 2006, 37, 943-948.

41. Hirva, P.; Tikka, H. Ab initio study on the interaction of anionic collectors with calcite and dolomite surfaces. Langmuir 2002, 18, 5002-5006. [CrossRef]

42. Gao, Z.Y.; Fan, R.Y.; John, R.; Sun, W.; Hu, Y.H. Surface broken bonds: An efficient way to assess the surface behaviour of fluorite. Miner. Eng. 2019, 130,15-23. [CrossRef]

43. Liu, M.; Li, H.; Jiang, T.; Liu, Q. Flotation of coarse and fine pyrochlore using octyl hydroxamic acid and sodium oleate. Miner. Eng. 2019, 132, 191-201. [CrossRef]

44. Barros, L.A.F.; Ferreira, E.E.; Peres, A.E.C. Floatability of apatites and gangue minerals of an igneous phosphate ore. Miner. Eng. 2008, 21, 994-999. [CrossRef]

45. Paiva, P.R.P.; Monte, M.B.M.; Sim O, R.A.; Gaspar, J.C. In situ AFM study of potassium oleate adsorption and calcium precipitate formation on an apatite surface. Miner. Eng. 2011, 24, 387-395. [CrossRef]

46. Li, C.W.; Gao, Z.Y. Effect of grinding media on the surface property and flotation behavior of scheelite particles. Powder Technol. 2017, 322, 386-392. [CrossRef]

47. Rong, G.Q.; Xia, Y.C.; Zhang, Y.F.; Guo, F.Y.; Wang, D.Y.; Zhang, R.; Xing, Y.W.; Gui, X.H. Effect of Comminution methods on low-rank coal bubble-particle attachment/detachment: Implications for flotation. Minerals 2019, 9, 452. [CrossRef]

48. Wenzel, R.N. Resistance of solid surfaces to wetting by water. Ind. Eng. Chem. 1936, 28, 988-994. [CrossRef] 
49. Cassie, A.B.D.; Baxte, S. Wettability of porous surfaces. Trans. Faraday Soc. 1994, 40, 546-551. [CrossRef]

50. Miller, J.D.; Veeramasuneni, S.; Drelich, J.; Yalamanchili, M.R.; Yamauchi, G. Effect of roughness as determined by microscopy on the wetting properties films. Polym. Eng. Sci. 1996, 36, 1849-1855. [CrossRef]

(C) 2020 by the authors. Licensee MDPI, Basel, Switzerland. This article is an open access article distributed under the terms and conditions of the Creative Commons Attribution (CC BY) license (http://creativecommons.org/licenses/by/4.0/). 